First results on the feeding ecology of the Transcaucasian water shrew Neomys teres (Soricomorpha: Soricidae) from Armenia

Sara CHURCHFIELD, Leszek RYCHLIK, Eduard YAVROUYAN and Kris TURLEJSKI

Sara CHURCHFIELD, Department of Anatomy and Human Sciences, King's College London, Henriette Raphael Building, Guy’s Campus, London SE1 1UL, England, e-mail: sara.churchfield@kcl.ac.uk

Leszek RYCHLIK, Mammal Research Institute, Polish Academy of Sciences, 17-230

Białowieża, Poland, e-mail: lrychlik@bison.zbs.bialowieza.pl; present address: Institute of Environmental Biology, Department of Biology, Adam Mickiewicz University, Umultowska 89, 61-614 Poznań, Poland

Eduard YAVROUYAN, Biological Faculty, Yerevan State University, Alec Manukian Ave. 1, 375-049 Yerevan, Armenia, e-mail: anpuorg@freenet.am

Kris TURLEJSKI, Laboratory of Neurobiology of Development and Evolution, Nencki Institute of Experimental Biology, 3 Pasteur Street, 02-093 Warsaw, Poland, e-mail: k.turlejski@nencki.gov.pl

Corresponding author: Sara CHURCHFIELD, Department of Anatomy and Human Sciences, King's College London, Henriette Raphael Building, Guy’s Campus, London SE1 1UL, England, e-mail: sara.churchfield@kcl.ac.uk 


\title{
First results on the feeding ecology of the Transcaucasian water shrew Neomys teres (Soricomorpha: Soricidae) from Armenia
}

Sara CHURCHFIELD, Leszek RYCHLIK, Eduard YAVROUYAN and Kris TURLEJSKI

\begin{abstract}
Microscopic examination of alimentary tracts of fourteen Neomys teres (Miller, 1908) from a mountainous region in northern Armenia produced the first data on the diet of this almost unknown species of conservation concern. Twenty-three different prey types were distinguished in summer-caught shrews, all invertebrates (14 terrestrial and 9 aquatic in origin). The dominant dietary items were Coleoptera and Diptera adults, Araneae, Opiliones and Lumbricidae plus freshwater crustaceans and Trichoptera larvae. Prey ranged from $<3$ to $>16 \mathrm{~mm}$ in length but those eaten most frequently were $6-10 \mathrm{~mm}$ in length. Although it was captured beside streams and rivers, aquatic prey comprised only $27 \%$ of dietary composition. Despite its morphological similarity to $N$. fodiens, its foraging niche more closely resembles that of upland populations of $N$. anomalus and its reliance on aquatic habitats remains equivocal.
\end{abstract}

Key-words: water shrew, diet, conservation, Armenia 


\section{Introduction}

Three species of water shrew belonging to the genus Neomys are found in Eurasia. $N$. fodiens (the Eurasian water shrew) and N. anomalus (the Mediterranean or southern water shrew) are widely distributed in allopatry and sympatry in Europe (Spitzenberger 1990; Mitchell-Jones et al. 1999; Krystufek et al. 2000), and their ecology has been subject to a number of studies (e.g., Rychlik 1997, 2000, 2005; Churchfield and Rychlik 2006 and papers cited therein). In contrast, the Transcaucasian water shrew, Neomys teres Miller, 1908 (previously known as N. schelkovnikovi Satunin, 1913: see Krystufek et al. 1998 and Hutterer 2005 ) is almost unknown. In comparison with the other two Neomys species, $N$. teres has a very limited distribution. It is found only in the Caucasian region, from south-eastern Russia to northern Iran and from north-eastern Turkey to Azerbaijan, with Armenia placed in the centre of its range (Krystufek et al. 2000). It is included on the IUCN list of threatened species under the category of Lower Risk (Least Concern) (Stone 1995; IUCN 2006) because it is locally abundant. However, with its restricted range and close association with pristine freshwater streams and rivers, it is vulnerable to habitat loss and degradation. Apart from a few anecdotal observations, its mode of life and ecology have not been investigated so far (Gureev 1979; Sokolov and Tembotov 1989; Stone 1995; Kryštufek and Vohralík 2001) and so its conservation needs cannot be properly addressed.

Neomys teres is the largest of the three Neomys species and it more closely resembles $N$. fodiens than $N$. anomalus with well-developed stiff hairs on the large hind feet and the relatively longer tail (Kryštufek and Vohralík 2001). This suggests that it should resemble $N$. fodiens in swimming and diving ability, and it is predicted to have a semi-aquatic mode of life. Indeed, anecdotal accounts (Sokolov and Tembotov 1989 citing Satunin 1915) suggest that $N$. teres mainly hunts under water, also under ice in winter and sometimes hunts insects or collects dead aquatic animals found on mud along stream-sides. Sokolov and Tembotov (1989) concluded that it has a broad diet, including many insects and their larvae, worms, 
snails, fish, spawn, frogs and tadpoles. However, there have been no detailed studies of feeding habits and foraging mode of $N$. teres to support these observation and speculations, and no data to indicate the extent of aquatic foraging.

The aim of this study was to investigate the feeding habits of $N$. teres and elucidate its foraging mode and trophic niche. We predicted that, given its size and morphological adaptations, it should demonstrate a high level of aquatic foraging. Since it is nowhere sympatric with N. fodiens (Sokolov and Tembotov 1989; Kryštufek et al. 2000), inter-specific competition is absent and so it was predicted to have a mode of life and trophic niche closely resembling its congenor and counterpart $N$. fodiens.

\section{Material and methods}

Alimentary tracts of $N$. teres were extracted from wet specimens kept in the collection of the Department of Biology, Yerevan (Erevan) State University (Armenia). These shrews were captured during investigations of the biodiversity of a little-studied mountainous region near the town of Dilijan (Dilizhan) (ca. $40^{\circ} 45^{\prime} \mathrm{N}, 44^{\circ} 53^{\prime} \mathrm{E}$, north of Lake Sevan), that were conducted in July and August of years 1987-1989 and 1999 (Fig. 1). All water shrews but one were captured along the River Aghstev (a tributary of River Kur) on a 4-5 km stretch passing the village of Haghardzin (Agartsin) and along its tributary streams, Haghardzin and BldanChay. Aghstev is a mountain river, descending $200 \mathrm{~m}$ at the investigated section (from 1550 to $1350 \mathrm{~m}$ ) and the relatively short tributary streams flow to the river from hills reaching 1800-2200 m. The hills are covered with deciduous forests (mainly Fagus and Quercus) with occasional clearings covered with herbaceous plants. At the bottoms of the steep-sided valleys the river and streams are passing through a habitat rich in bushes, grasses and herbaceous plants. One water shrew was captured near the town Ijevan, about $35 \mathrm{~km}$ down the river Aghstev, where the landscape is more open. 
Small mammals were captured in wooden box-traps and dry metal pitfalls placed along the water-courses. The traps were left open throughout day and night and were inspected each morning. Small mammals (including shrews) found dead in the traps were first preserved in 10\% formalin as voucher collections for the Yerevan State University. Before immersion in formalin their bellies were cut open along the midline. Subsequently, the specimens were transferred to $70 \%$ alcohol.

Analysis of the diets of shrews was based on microscopic examination of prey remains in the alimentary tracts taken from the preserved specimens. The trapping method was not ideal for the investigation of shrew diets: kill-trapping is generally more effective because stomachs are likely to contain larger quantities of undigested food remains compared with live-trapped individuals. However, the stomachs of $N$. teres contained many prey fragments and identifiable invertebrates were found in all the specimens examined. Since these shrews belong to a little-known and unusual species, any new information about their ecology was deemed useful. Identification of invertebrate prey remains was facilitated by use of a reference collection of potential prey items. Comparison of prey remains with a reference collection of invertebrates also permitted prey to be assigned to different body size classes. Individual arthropod prey were distinguished by their morphology and number of appendages or mouthparts, so permitting the number of occurrences of each prey type eaten by each shrew to be scored. Multiple items of the exactly the same prey type being eaten per shrew were very rare. It was not always possible to count the number of molluscs (identified by fragments of shell and/or radula) and earthworms (chaetae) eaten per shrew and so, unless there was clear evidence that more than one individual had been consumed, their presence was scored as a single occurrence for the purpose of the analyses.

The results were expressed as follows: \% frequency of occurrence of food items (the proportion of specimens containing a named food type); \% dietary occurrence of food items (the number of occurrences of a named food type as a proportion of the total occurrences of 
all food types); and \% volume composition of each food type (estimated by comparing the sizes of food remains with specimens in the reference collection). An index of the contribution of each food type was derived which incorporated the latter two measures:

$\%$ dietary composition $=\%$ dietary occurrence $+\%$ volume composition

\section{Results}

Fourteen specimens of $N$. teres were available for the diet study, including 5 adults (3F, 2M) and 9 subadults (3F, 5 M, 1 undetermined sex). Prey fragments were found in the alimentary tracts of all specimens. The mean number of prey items found per shrew was 6.2 (range 3-14). Twenty-three different prey types were distinguished (Table 1), all of them invertebrates. Fig. 2 shows the cumulative percentages of different prey taxa found as increasing numbers of diet samples were examined. Since all prey taxa were discovered by the $11^{\text {th }}$ sample it was concluded that sufficient samples were examined to be representative of the diet of $N$. teres from the study area.

Fourteen of the 23 prey types were terrestrial in origin but 9 were aquatic invertebrates. There was no evidence of vertebrate prey, such as fish or amphibians, having been eaten. The terrestrial prey items eaten most frequently were Coleoptera and Diptera adults and Araneae, followed by Opiliones and Lumbricidae (Table 1). Among aquatic prey, freshwater crustaceans (Asellus plus Gammarus) and Trichoptera larvae were the most important. In terms of the $\%$ dietary composition (incorporating total occurrence and volume contributions) the most important prey was Lumbricidae. Although Lepidoptera larvae appeared to be a major prey item, only two shrews had eaten these prey, one having devoured 12 caterpillars. 
Eleven of the 14 shrews (79\%) had eaten aquatic prey. Up to 6 different freshwater prey per shrew were consumed, of which Trichoptera larvae and crustaceans were predominant. Twenty-nine percent of prey occurrences were aquatic (33\% if mass consumption of Lepidoptera larvae by just one shrew is excluded). In terms of dietary composition, $27 \%$ was of aquatic origin (Table 1 ).

The size of prey items ranged from tiny araneids of $<3 \mathrm{~mm}$ in length to myriapods and earthworms of $>15 \mathrm{~mm}$. The size of earthworms could not be determined accurately from their remains (mostly chaetae) and so were given conservative estimates based upon minimum size in reference collections. Based on all occurrences, the prey eaten most frequently were small invertebrates of 6-10 $\mathrm{mm}$ or 3-5 $\mathrm{mm}$ in length (Fig. 3).

\section{Discussion}

One criticism of the study is that diet samples were taken mainly from specimens that had died in traps and so were unlikely to have full stomachs by the time of collection. However, all specimens contained recognisable prey remains and the total number of prey types found (23) was similar to that found in scats collected from live-trapped N. fodiens and N. anomalus (Churchfield and Rychlik 2006). Moreover, the mean number of prey items per shrew exceeded that found in Neomys scats by Churchfield and Rychlik (2006). Thus, we concluded that the data presented here are representative of the diet of $N$. teres living in northern Armenia around Dilijan.

Our data reveal that $N$. teres is a broad-spectrum feeder of aquatic and terrestrial invertebrates. Despite its relatively large size, Neomys teres resembles other shrew species (Sorex and Neomys) in consuming predominantly small prey of 3-10 $\mathrm{mm}$ in length, suggesting that it, too, is opportunistic with respect to prey size and eats common and abundant items (Castién and Gosálbez 1999; Churchfield and Sheftel 1994; Churchfield et al. 1997; Churchfield and Rychlik 2006). 
Our results do not support Satunin (cited in Sokolov and Tembotov 1989) that N. teres (schelkovnikovi) mainly hunts underwater, since most prey occurrences (71\%) were of terrestrial origin. Neither do they provide evidence to support the suggestion of Sokolov and Tembotov (1989) that $N$. teres catches amphibians and fish (although our sample size is small).

Neomys teres combined aquatic foraging with terrestrial hunting, suggesting a foraging mode similar to that of other Neomys species. Studies of N. fodiens and N. anomalus have demonstrated that, although both species will hunt for aquatic prey, the former is better adapted for swimming and diving and this is reflected in its choice of micro-habitat and foraging mode. Compared with $N$. anomalus, $N$. fodiens is more inclined to swim and dive, it occupies microhabitats closer to deep water and a larger proportion of its prey are captured underwater (Kuvikova 1985a; Rychlik 1997, 2000; Churchfield and Rychlik 2006; Soares and Rychlik 2004). Accordingly, 20\% of prey of summer-caught $N$. fodiens was aquatic compared with only $11 \%$ for $N$. anomalus (Churchfield and Rychlik 2006). Although N. teres externally resembles N. anomalus (Kryštufek and Vohralík 2001), its adaptations to semi-aquatic life are better developed (longer tail and larger hind feet, more pronounced fringes on hind feet, and eyes hidden in the fur). These features more closely resemble $N$. fodiens (Gureev 1979; Kryštufek et al. 1998, 2000; Kryštufek and Vohralík 2001) suggesting that it is a similarly good swimmer and diver. Aquatic prey comprised $27 \%$ of the diet of summer-caught $N$. teres, more closely resembling $N$. fodiens than $N$. anomalus, as predicted. Also, its close association with streams or small rivers and apparent rarity in other habitats (Sokolov and Tembotov 1989; Kryštufek et al. 1998; 2000; Kryštufek and Vohralík 2001) shows closer overlap with the habitat preferences of $N$. fodiens than $N$. anomalus.

The amount of aquatic foraging by $N$. fodiens and $N$. anomalus is very variable and it reflects the habitat type. In lowland habitats (e.g., alder forest, sedge swamp), where availability of terrestrial prey is high, aquatic prey comprise only $11-20 \%$ of the diet of $N$. 
fodiens and 0-11\% of N. anomalus (Kuvikova 1985a; Churchfield and Rychlik 2006).

However, aquatic prey of $N$. fodiens may exceed $50 \%$ in some lowland habitats (such as water-cress beds - Churchfield 1984). In upland habitats (such as mountain streams) the proportion of aquatic prey in the diets of water shrews is usually much higher: $83-95 \%$ in $N$. fodiens (Niethammer 1978; Kuvikova 1985b; DuPasquier and Cantoni 1992; Castién 1995) and $17-61 \%$ of $N$. anomalus (Niethammer 1978; Kuvikova 1987). Therefore, we expected a high proportion of aquatic prey in the diet of $N$. teres living along mountain streams and small rivers. Contrary to this prediction, only $27 \%$ of its diet comprised aquatic prey. This more closely resembles the diet of $N$. anomalus from upland populations rather than $N$. fodiens. Also a high consumption of Lepidoptera, Araneae and Lumbricidae, found in the present study, resembles feeding habits of $N$. anomalus (Kuvikova 1985a; Churchfield and Rychlik 2006). As to Lepidoptera, the result is perhaps incidental, since only two shrews ate them, but eating of spiders and earthworms seems to be usual.

For conservation and management purposes it is important to understand the food and habitat requirements of a species. Our study has provided the first data on the feeding habits of $N$. teres in an attempt to elucidate its foraging requirements but, with its relatively low consumption of freshwater invertebrates, its reliance on aquatic habitats remains equivocal. Further investigation of this elusive and unusual species is needed in different parts of its range and in different seasons to fully reveal its feeding ecology and mode of life.

\section{References}

Castién, E. 1995. The diet of Neomys fodiens in the Spanish Western Pyrenees. Folia Zool. 44: 297-303.

Castién, E., and Gosálbez, J. 1999. Habitat and food preferences in a guild of insectivorous mammals in the Western Pyrenees. Acta Theriol. 44: 1-13.

Churchfield, S. 1984. Dietary separation in three species of shrew inhabiting water-cress beds. J. Zool. (Lond.), 204: 211-228. 
Churchfield, S., and Rychlik, L. 2006. Diets and coexistence in Neomys and Sorex shrews in Białowieża Forest, eastern Poland. J. Zool. (Lond.). 269: 381-390.

Churchfield, S., and Sheftel, B.I. 1994. Food niche overlap and ecological separation in a multi-species community of shrews in the Siberian taiga. J. Zool. (Lond.), 234: 105124.

Churchfield, S., Sheftel, B.I., Moraleva, N.V., and Shvarts, E.A. 1997. Habitat occurrence and prey distribution of a multi-species community of shrews in the Siberian taiga. J. Zool. (Lond.), 241: 55-71.

DuPasquier, A. and Cantoni, D. 1992. Shifts in benthic macroinvertebrate community and food habits of the water shrew, Neomys fodiens (Soricidae, Insectivora). Acta Oecol. 13: 81-99.

Gureev, A.A. 1979. Nasekomoyadnye (Mammalia, Insectivora). Ezhi, kroty i zemleroiki (Erinaceidae, Talpidae, Soricidae). V serii: Fauna SSSR. Mlekopitayushchie. Izdatiel'stvo "Nauka", Leningradskoe Otdelenie, Leningrad. [In Russian] Hutterer, R. 2005. Order Soricomorpha. In: Mammal Species of the World, a taxonomic and geographic reference. Vol. 1. Edited by D.E. Wilson and D.M. Reeder D.M. $3^{\text {rd }}$ Edition. Johns Hopkins Univ. Press, Baltimore. pp. 220-311.

IUCN 2006. 2006 IUCN Red List of Threatened Species. <www.iucnredlist.org> Kryštufek, B., Davison, A., and Griffiths, H.I. 2000. Evolutionary biogeography of water shrews (Neomys spp.) in the western Palaearctic Region. Can. J. Zool. 78: 1616-1625.

Kryštufek, B., and Vohralík, V. 2001. Mammals of Turkey and Cyprus: Introduction, checklist, Insectivora. Zgodovinsko društvo za južno Primorsko, Znanstvenoraziskovalno središče Republike Slovenije, Koper, Slovenia.

Kryštufek, B., Vohralík, V., and Kurtonur, C. 1998. A new look at the identity and distribution of water shrews (Neomys spp.) in Turkey. Z. Saugetierkd. 63: 129-136.

Kuvikova, A. 1985a. The food of some species of the family Soricidae (Insectivora) in the alder forest of the Jursky sur wetland. Biológia (Bratislava), 40: 181-187. [In Slovak with English abstract]. 
Kuvikova, A. 1985b. Zur Nahrung der Wasserspitzmaus, Neomys fodiens, in der Slowakei. Biológia (Bratislava), 40: 563-572.

Kuvikova, A. 1987. Zur Nahrung der Sumpfspitzmaus Neomys anomalus Cabrera, 1907 (Insectivora, Soricidae) in der Slowakei. Lynx (Praha), 23: 55-62.

Mitchell-Jones, A.J., Amori, G., Bogdanowicz, W., Kryštufek, B., Reijnders, P.J.H., Spitzenberger, F., Stubbe, M., Thissen, J.B.M., Vohralík, V., and Zima, J. (eds) 1999. The atlas of European mammals. T and AD Poyser Ltd, London.

Niethammer, J. 1978. Weitere Beobachtungen über Wasserspitzmäuse der Arten Neomys fodiens und N. anomalus. Z Saeugetierkd. 43: 313-321.

Rychlik, L. 1997. Differences in foraging behaviour between water shrews: Neomys anomalus and Neomys fodiens. Acta Theriol. 42: 351-386.

Rychlik, L. 2000. Habitat preferences of four sympatric species of shrews. Acta Theriol. 45: 173-190.

Rychlik, L. 2005. Overlap of temporal niches among four sympatric species of shrews. Acta Theriol. 50: 175-188.

Soares, H.M., and Rychlik, L. 2004. Swimming and diving behaviour of two species of water shrews, Neomys anomalus and Neomys fodiens (Insectivora: Soricidae). In: Contributions to the $5^{\text {th }}$ International Symposium on Physiology, Behaviour and Conservation of Wildlife, Berlin, Germany, 26-29 September 2004. Edited by C. Voigt and H. Hofer. Advances in Ethology 38, Suppl. to Ethology, p. 79.

Sokolov, V.E., and Tembotov, A.K. 1989. Mlekopitayushchie Kavkaza: Nasekomoyadnye [Mammals of the Caucasus: Insectivores]. V serii: Pozvonochnye Kavkaza. Nauka, Moskva. [In Russian]

Spitzenberger, F. 1990. Gattung Neomys Kaup, 1829. In: Handbuch der Säugetiere Europas. Band 3/I. Insektenfresser, Herrentiere. Edited by J. Niethammer and F. Krapp. AulaVerlag, Wiesbaden, Germany, pp. 313-374.

Stone, R.D. 1995. Eurasian insectivores and tree shrews. Status Survey and Conservation Action Plan. IUCN, Gland, Switzerland. 
Table 1: Diet of Neomys teres from Armenia $(n=14)$

\begin{tabular}{|c|c|c|}
\hline & $\begin{array}{l}\% \text { frequency } \\
\text { of occurrence }\end{array}$ & $\begin{array}{c}\% \text { dietary } \\
\text { composition }\end{array}$ \\
\hline \multicolumn{3}{|l|}{ TERRESTRIAL PREY } \\
\hline Coleoptera: Staphylinidae & 14.3 & 2.4 \\
\hline Other Coleoptera adults indet. & 35.7 & 6.0 \\
\hline Coleoptera larvae & 21.4 & 2.9 \\
\hline Diptera adults: Culicidae & 21.4 & 2.5 \\
\hline Diptera adults indet. & 35.7 & 4.8 \\
\hline Diptera larvae: Tipulidae & 14.3 & 2.4 \\
\hline Diptera larvae indet. & 7.1 & 1.2 \\
\hline Lepidoptera larvae & 14.3 & 15.7 \\
\hline Heteroptera & 14.3 & 1.9 \\
\hline Chilopoda: Geophilomorpha & 7.1 & 1.7 \\
\hline Araneae & 71.4 & 9.9 \\
\hline Opiliones & 42.9 & 5.0 \\
\hline Gastropoda: Slugs & 7.1 & 1.2 \\
\hline Lumbricidae & 42.9 & 15.5 \\
\hline \multicolumn{3}{|l|}{ AQUATIC PREY } \\
\hline Trichoptera larvae & 42.9 & 8.4 \\
\hline Plecoptera nymphs & 21.4 & 2.9 \\
\hline Ephemeroptera nymphs & 14.3 & 1.9 \\
\hline Insect nymph indet. & 14.3 & 1.9 \\
\hline Coleoptera adults & 7.1 & 1.2 \\
\hline Coleoptera larvae & 7.1 & 1.2 \\
\hline Diptera larvae: Chironomidae & 7.1 & 0.8 \\
\hline Gammarus & 21.4 & 3.2 \\
\hline Asellus & 35.7 & 5.4 \\
\hline
\end{tabular}




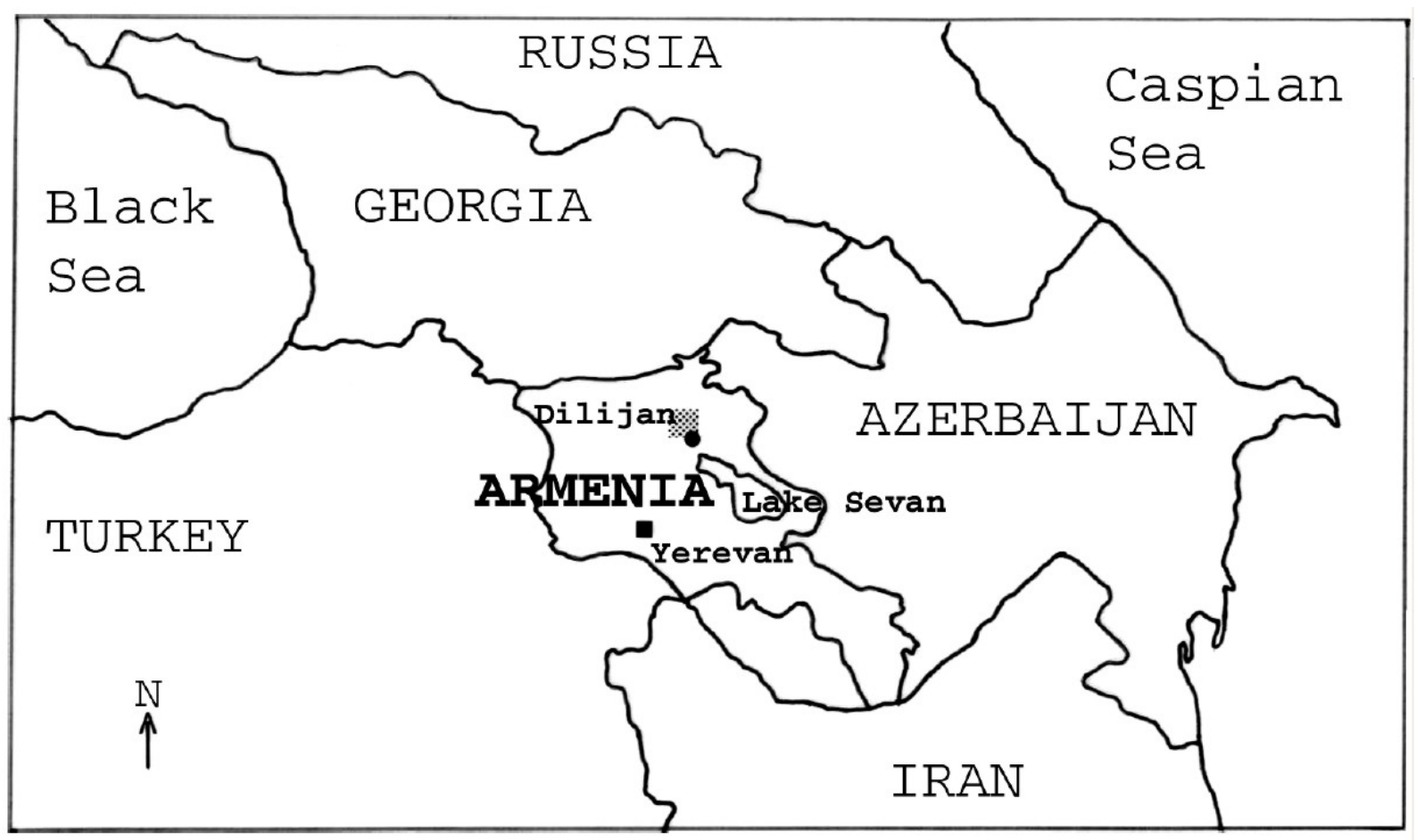

Figure 1. Map showing the location of the study area (stippled) near the town of Dilijan, Armenia. 


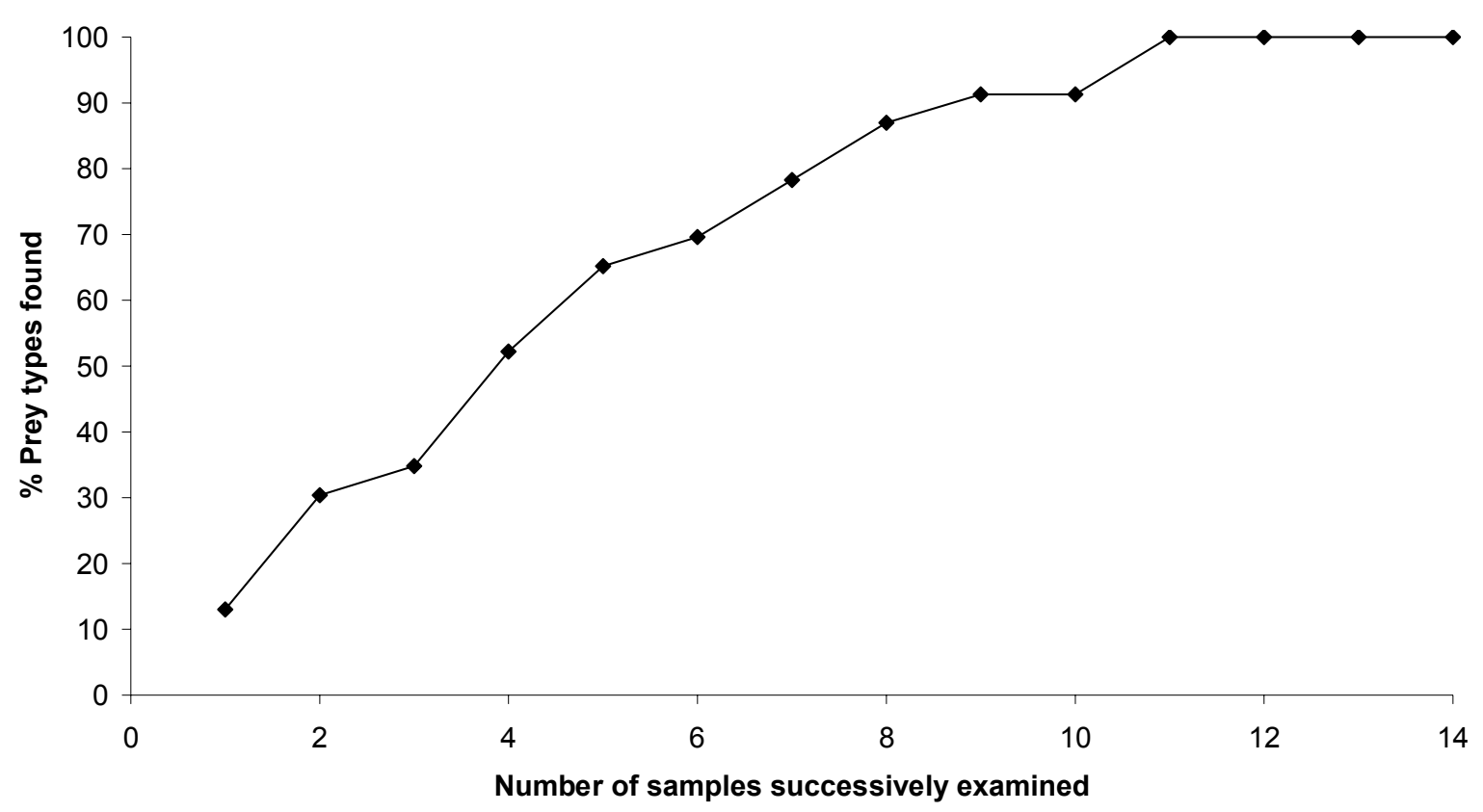

Figure 2. Cumulative number of prey types found as successive samples of alimentary tracts of $N$. teres were examined. 


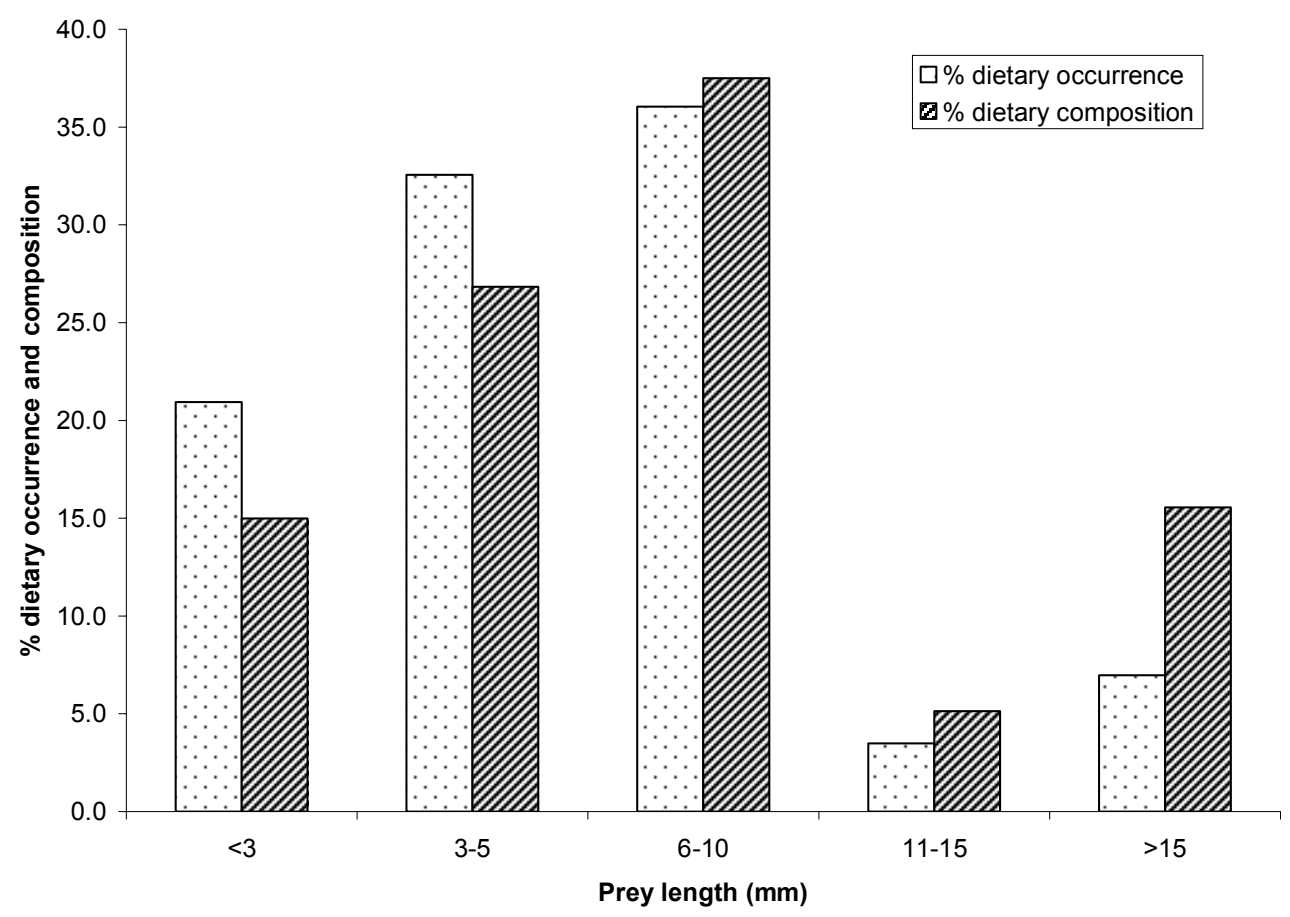

Figure 3. Prey sizes eaten by $N$. teres from the Dilijan region, northern Armenia. 